\title{
Cpkk1, MAPKK of Cryphonectria parasitica, Is Necessary for Virulence on Chestnut
}

\author{
Laura Rostagno, Antonio Prodi, and Massimo Turina
}

First and third authors: Istituto di Virologia Vegetale, CNR, Strada delle Cacce 73, 10135 Torino, Italy; and second author: DISTA, Università di Bologna, Via Fanin 40, 40127 Bologna, Italy. Accepted for publication 12 June 2010.

\section{ABSTRACT}

Rostagno, L., Prodi, A., and Turina, M. 2010. Cpkk1, MAPKK of Cryphonectria parasitica, is necessary for virulence on chestnut. Phytopathology 100:1100-1110.

The role of Cpkk1, a mitogen-activated protein kinase from Cryphonectria parasitica, was investigated by generating a number of mutant strains that overexpress, under the control of the cryparin promoter, both the wild-type protein and its allele with an extensive deletion in the catalytic domain. Furthermore, a hairpin construct was built and expressed to cause specific silencing of Cpkk1 mRNA transcripts.
Specific mRNA silencing or overexpression was confirmed on both Northern and Western blot analysis. Selected $C$. parasitica strains with Cpkk1 either silenced or overexpressed were evaluated for their biological characteristics, including virulence on European chestnut, growth on different substrates, conidial sporulation, and resistance to cellwall-degrading enzymes. Silencing of Cpkk1 and the overexpression of a defective Cpkk1 correlated with a marked reduction in virulence on 3 -year-old chestnut trees, with no statistically significant effect on fungal growth in the various conditions tested.
The filamentous ascomycete Cryphonectria parasitica, the causal agent of chestnut blight, caused the destruction of North American chestnut forests in the early 20th century (25). Many viruses of the Hypoviridae family can alter the virulence of $C$. parasitica. Virus-caused hypovirulence has been employed in the biological control of chestnut blight disease (5). Infection of $C$. parasitica by Cryphonectria hypovirus 1 (CHV1) alters fungal development (e.g., diminished asexual and sexual sporulation, altered pigmentation, and reduced virulence on chestnut) $(18,40$, 47,60). Viral infection causes pleiotropic effects, as demonstrated by differential display (11) and cDNA microarrays $(1,2)$, including up- or downregulation of genes putatively controlled by the signal transduction pathways.

Various genes encoding components of signal transduction pathways in $C$. parasitica have been cloned and characterized $(12,13,19,30-33,48,61)$. Preliminary observations suggest that signal transduction pathway components could be targets for CHV1 and linked to hypovirulence (60). Several of these genes are part of G-protein signalling cascades $(13,30,31)$ while others are involved in mitogen-activated protein kinase (MAPK) pathways $(12,32-33,48,61)$.

In eukaryotic cells, the MAPK pathways involved in the transduction of a variety of extracellular signals and the regulation of different developmental processes $(24,55)$ appear to be well preserved in a variety of organisms ranging from yeast to humans $(26,55)$ and generally contain three protein kinases that act in series: MAPK kinase kinase (MAPKKK or MEKK), MAPK kinase (MAPKK or MEK), and MAPK. MAPK pathways play an important role in the virulence of fungal pathogens $(63,70)$, as

Corresponding author: M. Turina; E-mail address: m.turina@ivv.cnr.it

* The $\boldsymbol{e}$-Xtra logo stands for "electronic extra" and indicates that the online version contains two supplemental figures. Figure 6 appears in color online.

L. Rostagno and A. Prodi contributed equally to this article.

doi:10.1094/PHYTO-02-10-0044

(C) 2010 The American Phytopathological Society observed in many phytopathogenetic fungi, such as Botrytis cinerea (57,71), Candida albicans $(3,17)$, Claviceps purpurea (42), Cochliobolus heterostrophus (37), Colletotricum lagenarium (58), Fusarium graminearum (27), Fusarium oxysporum (20), Magnaporthe grisea $(64,65)$, Mycosphaerella graminicola (35), and Ustilago maydis $(29,43)$.

The aim of this study was to examine the potential functions of Cpkk1, a previously cloned and described MAPKK (61), and to determine whether it plays a role in altering Cryphonectria parasitica virulence. The (possibly indirect) viral modulation of Cpkk1 has been demonstrated (61); in particular, CHV1 infection prolongs the maintenance of the Cpkk1 hyperphosphorylated states. In this study, we attempted to obtain a functional characterization of Cpkk1 by overexpression of both the wild-type and the truncated forms of the protein, as well as specifically silencing the gene of interest. Our results demonstrate that a functional Cpkk1 from $C$. parasitica is necessary for causing canker symptoms on chestnut trees.

\section{MATERIALS AND METHODS}

Fungal strains and culturing. The $C$. parasitica strains in our experiments were EP67 (American Type Culture Collection [ATCC] no. 38753) and the isogenic virus-infected strain EP802 (ATCC no. 52574). The fungal strains were maintained on potato dextrose agar containing methionine $(100 \mathrm{mg} / \mathrm{liter})$ and biotin (100 mg/liter) (PDAmb) (4) at $26^{\circ} \mathrm{C}$ under constant light. The fungal mycelium was harvested as circular agar plugs $(5 \mathrm{~mm}$ in diameter), macerated in a blender, and used as initial inoculum for EP complete medium liquid cultures and for EP minimal liquid cultures $(49,67)$. The cultures were then grown for $48 \mathrm{~h}$ at $26^{\circ} \mathrm{C}$ under shaking at $100 \mathrm{rpm}$. The mycelium was harvested by filtration through a single layer of Miracloth (Merck KGaA, Darmstad, Germany) placed over a Buchner funnel and blotted onto paper towels to remove excess moisture, frozen at $-80^{\circ} \mathrm{C}$, and then lyophilized for $48 \mathrm{~h}$. The lyophilized mycelium was then used for DNA, RNA, and protein extraction. 
Plasmid constructs to overexpress Cpkk1. To overexpress Cpkk1, we started with the expression vector pCryGenHyg (Fig. $1 \mathrm{~A})$, a plasmid expressing the wild-type cryparin gene $(\approx 3.6$ $\mathrm{kbp}$ ), modified to obtain pCryGenBam- (23) and ligated to the Hygromycin B phosphotransferase gene derived from the plasmid pCB1004 (10). Using polymerase chain reaction (PCR) sitedirected mutagenesis, a unique BamHI restriction site was introduced into the cryparin coding sequence amplifying the expression vector pCryGenHyg with the oligonucleotides CryBamHI2022F and CryBamHI-1448R (Table 1). The vector was amplified with the Expand Long Template kit (Roche Diagnostics, Penzberg, Germany) in a two-step reaction: the first 5 cycles were performed at an annealing temperature of $55^{\circ} \mathrm{C}$, which was then increased to $65^{\circ} \mathrm{C}$ for the following 30 cycles. The extension time was $3 \mathrm{~min}$ at $68^{\circ} \mathrm{C}$. The amplified PCR fragment $(\approx 7.3 \mathrm{kbp})$ was digested with BamHI and self-ligated to obtain the plasmid pCryGenBam (Fig. 1B).
A complete version of the cpkkl coding sequence was amplified with the oligonucleotides Cpkk1BamHI-803F and Cpkk1BamHI-2696R (Table 1) in order to introduce a BamHI restriction site at the $5^{\prime}$ and $3^{\prime}$ ends of the coding sequence. Amplification was carried out using Taq polymerase (Polymed, Sambuca, Italy) at an annealing temperature of $65^{\circ} \mathrm{C}$ and an extension time of $3 \mathrm{~min}$ at $72^{\circ} \mathrm{C}$. After cloning the cpkkl gene into a pGEM-T Easy vector (Promega Corp., Madison, WI), the gene was introduced into the expression vector pCryGenBam under the control of the cryparin promoter. The expression vector pCryGenBam had been previously digested with BamHI and dephosphorylated using shrimp alkaline phosphatase (Promega Corp.). The final expression vector was called pCryCpkk1 (Fig. 1C). The intermediate expression vector pCryGenBam was used as a negative control in our experiments.

Each clone obtained from a PCR step was sequenced in both the promoter and the coding regions to exclude the possi-

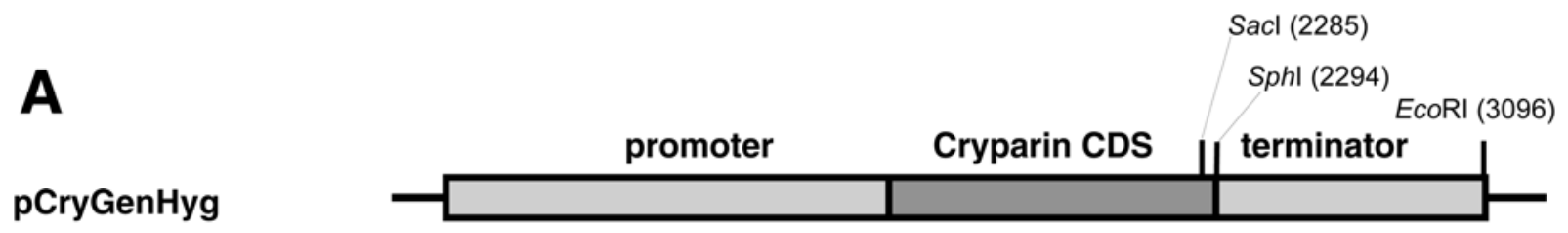

B

pCryGenBam
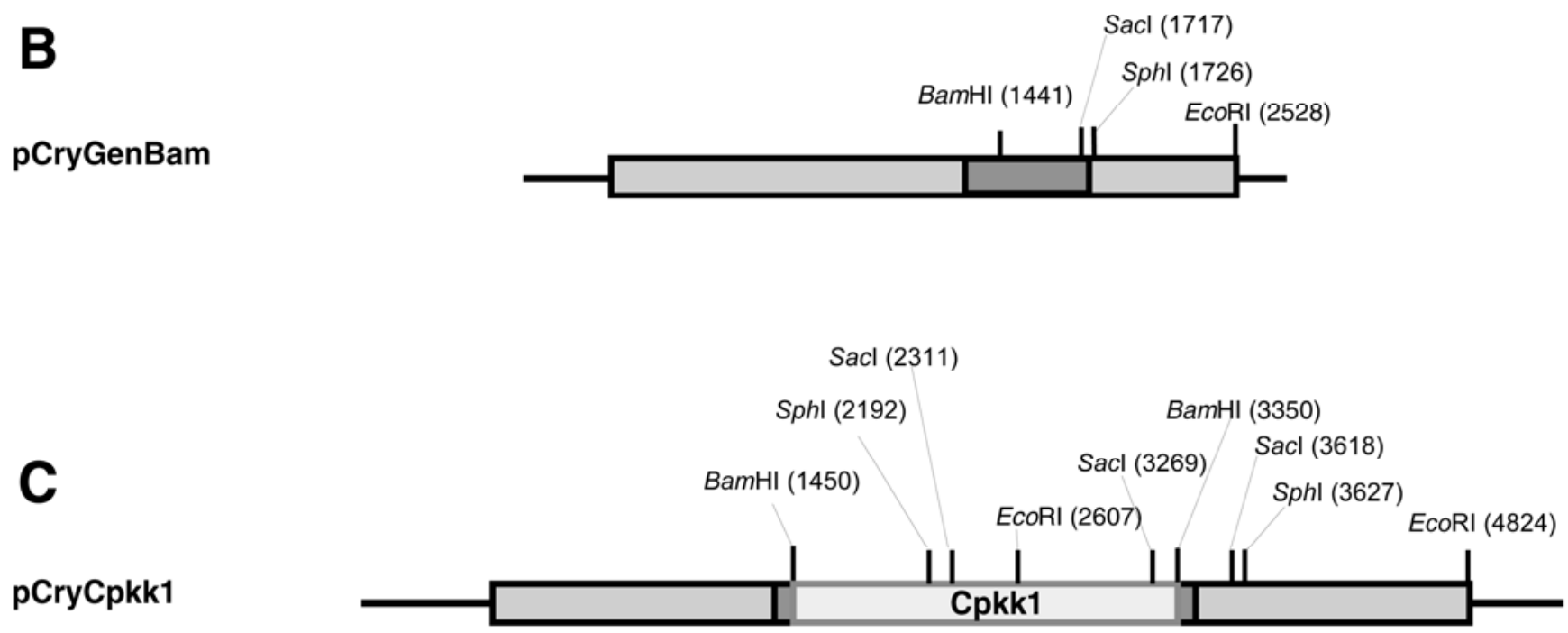

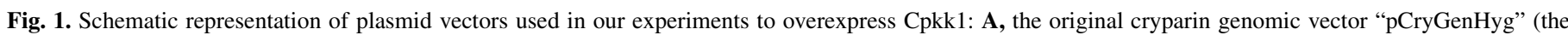

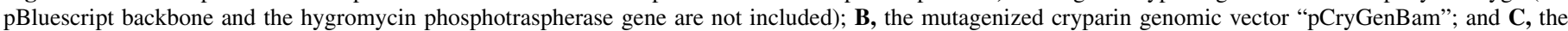
plasmid overexpressing Cpkk1 "pCryCpkk1".

TABLE 1. Oligonucleotides used in this study

\begin{tabular}{|c|c|}
\hline Oligonucleotide name $\mathrm{z}$ & Sequence \\
\hline CryBamHI-2022F & 5'AAAGGATCC-TAAGGGGATTCCGAAGTC3' \\
\hline CryBamHI-1448R & 5'AAAGGATCC-AAATGACCCGAAGACTT3' \\
\hline Cpkk1BamHI-803F & 5'AAAGGATCC-CGCCGCATGATG3' \\
\hline Cpkk1BamHI-2696R & 5'AAAGGATCC-TCTCTCACTTTGA3' \\
\hline CryBamHI-2028F & 5'AAAGGATCC-GATTCCGAAGTCTGATAGCA3' \\
\hline CryBamHI-2022R & 5'AAAGGATCC-CAGACCAACTGGGTCC3' \\
\hline Cpkk1BamHI-838F & 5'AAAGGATCC-GATCAAGCTGCACCTATCA3' \\
\hline Cpkk1PstI-1458R & 5'TTTCTGCAG-CGTACCGTGTGGTTTACC $3^{\prime}$ \\
\hline Cpkk1PstI-1575R & 5'TTTCTGCAG-CAGGGTCACCTCGTCCATA3' \\
\hline Cpkk1PacI-1840R & 5'AAATTAATTAA-TGACGTCTGGATCTGG3' \\
\hline Cpkk1PacI-2213F & 5'AAATTAATTAA-CAGCTACTACATGGCGC3' \\
\hline
\end{tabular}

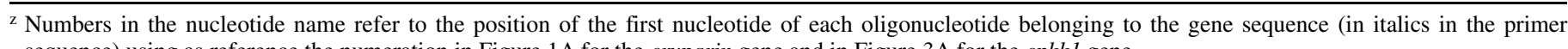
sequence) using as reference the numeration in Figure 1A for the cryparin gene and in Figure 3A for the cpkk1 gene. 
bility that mutations had been introduced during template amplification.

Plasmid constructs to overexpress the truncated form of Cpkk1. To delete a portion of $\approx 400 \mathrm{bp}$ in the conserved region of the catalytic domain present at the C-terminal end of the protein (Fig. 2A) (61), we amplified the construct created for the overexpression of Cpkk1, called pCryCpkk1, with the oligonucleotides Cpkk1PacI-1840R and Cpkk1PacI-2213F (Table 1). A Phusion high-fidelity DNA Polymerase kit (Finnzymes, Espoo, Finland) was used for amplification in a two-step reaction, with the first 5 cycles at an annealing temperature of $52^{\circ} \mathrm{C}$ and an extension time of $4 \mathrm{~min}$ at $72^{\circ} \mathrm{C}$ followed by 30 cycles at an annealing temperature of $61^{\circ} \mathrm{C}$. The resulting 8.5-kbp PCR amplicon was digested with $P a c I$ and self-ligated, and the resulting plasmid, named pCryCpkk1 $\Delta$, was used to transform $C$. parasitica spheroplasts. Insertion of the PacI site into the sequence also introduced an early termination codon that prematurely truncated the protein to a predicted molecular mass of $29 \mathrm{kDa}$.

Plasmid constructs for Cpkk1 silencing. The expression vector pCryGenHyg (described above) was used as the initial template to build a construct to silence $c p k k 1$. Through PCR sitedirected mutagenesis, a unique BamHI restriction site was intro-
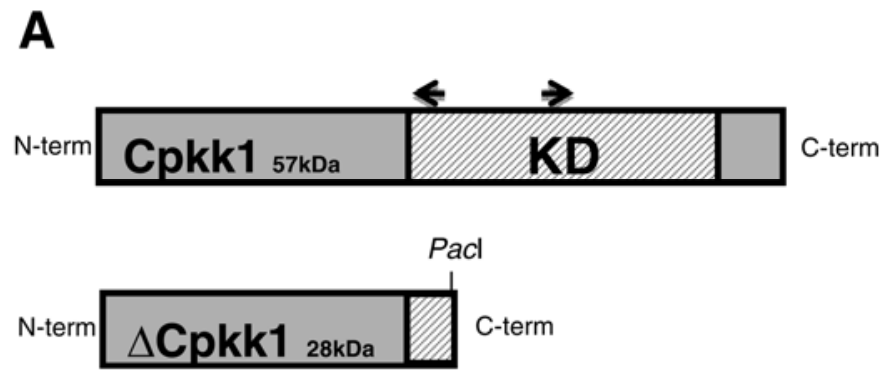

B

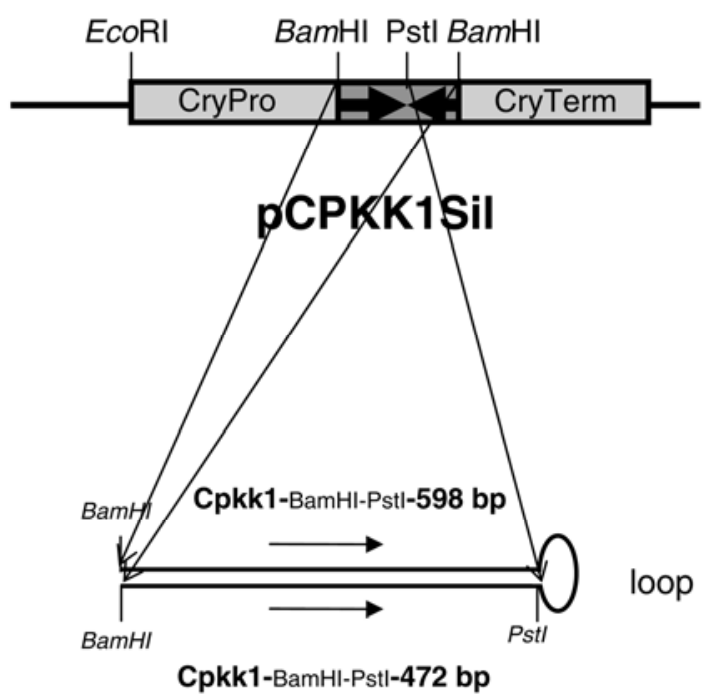

Fig. 2. A, Schematic representation of truncation in the catalytic domain of Cpkk1 in the C-terminal half of the protein due to premature termination of translation at the $\mathrm{Pac}$ I site and the final vector derived from its insertion in the expression vector resulting in the plasmid "pCryCpkk1 $1 \Delta$ ". Arrows indicate the position of the oligonucleotides used for mutagenesis. $\mathrm{KD}=$ kinase domain. B, Schematic representation of the expression vectors used for silencing Cpkk1, including the hairpin constructs and the final expression vector pCpkk1sil. Arrows indicate the orientation of the mRNA in the coding sense. Restriction enzymes used in the cloning steps are reported. duced at position 710 of the cryparin sequence (GenBank accession no. L09559). The oligonucleotides CryBamHI-2028F and CryBamHI-2022R (Table 1) were used with the Expand Long Template kit (Roche Diagnostics) with an annealing temperature of $65^{\circ} \mathrm{C}$ and an extension time of $7 \mathrm{~min}$. The 7-kbp amplified product was digested with $\mathrm{BamHI}$ and self-ligated resulting in an intermediate plasmid called pTo1.

To modify the $c p k k l$ sequence for induction of post-transcriptional gene silencing (PTGS), the cpkkl gene was amplified by PCR from $C$. parasitica genomic DNA serving as the template in two distinct reactions with a single forward oligonucleotide (Cpkk1BamHI-838F) and two different reverse oligonulceotides (Cpkk1PstI-1458R and Cpkk1PstI-1575R) (Table 1). Two different Cpkk1 PCR products were obtained: a 598-bp amplicon (fragment A) and a 472-bp amplicon (fragment B), each containing both BamHI and PstI sites, respectively. Both fragments were cloned into pGEM-T easy vector (Promega Corp.) following the manufacturer's protocol. The amplified fragment B, obtained by cutting pGEM-T with BamHI and PstI, was ligated into pGEM-T containing the fragment $A$ in order to obtain an inverted repeat with BamHI at the end (Fig. 2B). The inverted repeat was then cloned into pTo1 vector using the engineered BamHI restriction site. The final plasmid to induce $c p k k 1$ silencing was called pCPKK1sil (Fig. 2B).

Transformation of $C$. parasitica spheroplasts. Spheroplasts of C. parasitica strain EP67 were transformed as described (15) with modifications (59). Selected transformants growing on the selective medium were chosen for further studies and single spored to ensure that each fungal transformant derived from a single nucleus.

RNA extraction for quantitative reverse-transcription PCR, Northern blot, and siRNAs analysis. The mRNA expression of Cpkk1 in the transformed strains was evaluated by quantitative reverse-transcription PCR (qRT-PCR). Fungal RNA was extracted using a RiboPure-Yeast kit (Ambion, Austin, TX). The extracted RNA was treated with DNase (Ambion), then retrotranscribed using a High-Capacity cDNA kit (Applied Biosystems, Foster City, CA) and diluted in a 1:5 ratio in sterile water.

The relative quantification of cpkk1 mRNA expression was estimated by comparative cycle threshold $(\Delta \Delta \mathrm{Ct})$ using oligonucleotides, probes, and reaction conditions as previously described in detail (52).

The results of Cpkk1 overexpression and silencing obtained by qRT-PCR were confirmed by Northern blot analysis as previously described (66). Radioactive riboprobes were prepared using a Maxiscript kit (Ambion) following the manufacturer's instructions, linearizing the plasmid template pGemT-Cpkk1 with SphI, and using SP6 RNA polymerase (Fig. 3A).

Small RNA purification and separation on acrylamide Trisborate-EDTA (TBE)-urea gels were performed as detailed previously (28), except that total RNA was extracted as described above and siRNAs were concentrated using a mirVana kit (Ambion) following the manufacturer's instructions. The cpkk1 riboprobe, in this case, was prepared by cutting the plasmid template pGemT-Cpkk1 with ApaI in order to preserve full-length cpkk1 mRNA transcripts. The riboprobe was then digested with an equal volume $(50 \mu \mathrm{l})$ of $2 \times$ carbonate buffer $\left(120 \mathrm{mM} \mathrm{Na}_{2} \mathrm{CO}_{3}\right.$, $80 \mathrm{mM} \mathrm{NaHCO}, \mathrm{pH} 10.2$ ) and neutralized with $20 \mu \mathrm{l}$ of $3 \mathrm{M}$ NaAcetate ( $\mathrm{pH}$ 5.2). Hybridization and washes were performed using the ULTRAhyb oligo hybridization buffer and NorthernMAX High stringency Wash Solution no. 2 (both from Ambion) as suggested by the manufacturer.

DNA extraction and Southern blot analysis. DNA was extracted from $C$. parasitica according to the protocol previously described (59) and Southern blot analysis was performed as described (54). After digestion with appropriate restriction enzymes (SacI, SphI, and EcoRI), the DNA was transferred to Hybond N+ (Amersham Biosciences, Piscataway, NJ) after separa- 
tion in a $1 \times$ TBE, $0.8 \%$ agarose gel. RNA derived in vitro from the same clone and in the same conditions described for the Northern blot analysis was used as a probe in the Southern blot analysis.

Protein extraction and Western blot analysis. Proteins of the selected strains were extracted in buffer A prepared and used as described previously (61). Western blot analysis was carried out as previously detailed (61) with the antibodies at a dilution rate of 1:2000 for Cpkk1 in 1× Tris-buffered saline, $0.2 \%$ Tween-20, and $7 \%$ milk. Secondary anti-rabbit immunoglobulin G HRP conjugate (Promega Corp.) was diluted 1:5,000 in the same buffer. A chemiluminescent substrate, SuperSignal West Pico (Thermo Scientific, Rockford, IL), was used to detect the presence of secondary antibody.

Evaluation of growth on different media. Growth of mutated strains was evaluated on two different solid media: PDAmb and EP minimal (49). The fungal growth rate was estimated as the diameter of the colony measured 5 days postinoculation (dpi). At least three replicates were considered for all experimental conditions. The results were analyzed by one-way analysis of variance (ANOVA); Tukey's highly significant difference (HSD) test was used to discriminate statistically significant differences.

Evaluation of fungal sporulation. Asexual sporulation of $C$. parasitica mutated strains was evaluated after 3 weeks of growth on PDAmb under the conditions described previously (28). To estimate conidial production, a normalized spore suspension from each plate was prepared and the spores were counted microscopically with a hemacytometer. For each strain, we analyzed three replicates. The statistical significance of the results was analyzed as described above.

Pathogenicity tests. The mutated strains of $C$. parasitica were used to inoculate 3-year-old European chestnut trees (Castanea sativa). A bark plug ( $5 \mathrm{~mm}$ in diameter) was removed and the wound covered with the mycelial growth harvested from a PDAmb plate. The inoculated wound was then wrapped with parafilm to prevent desiccation. For each stand, one mutated strain and the control strain $67 \mathrm{Hyg}$ were inoculated $30 \mathrm{~cm}$ apart, and each stand replicated twice. This sequence was repeated three times in three different $C$. sativa stands. The canker area was measured every 2 weeks beginning $30 \mathrm{dpi}$, and the canker area was approximated to an ellipse (51). The differences between the canker area generated by the transformed strains and the control strain were evaluated using two-way ANOVA.

Pathogenicity was also evaluated on Golden Delicious apple fruit as previously described (22). The apple fruit were inoculated with plugs of the mycelium as described (28), except that, here, four inoculations were done per fruit and each strain was replicated six times. The fruit were incubated in a humidity chamber at room temperature for 3 weeks. The canker area was approximated to a circle and the lesion radius was measured at 5 and 10 dpi. The results were analyzed by one-way ANOVA as previously described.

Resistance to cell-wall-degrading enzymes. We evaluated the resistance of fungal cell walls to digestion by selected lytic enzymes for Cpkk1-silenced strains. The selected strains were cultured in $500 \mathrm{ml}$ of EPc in total absence of light at $120 \mathrm{rpm}$ for $23 \mathrm{~h}$. The mycelium was harvested by centrifugation at 10,000 rpm for $10 \mathrm{~min}$ at $4^{\circ} \mathrm{C}$. The mycelial pellet was washed twice with an aqueous solution of $0.6 \mathrm{M} \mathrm{MgSO}_{4}$ and then collected by vacuum filtration using Miracloth. Mycelium (30 mg) was resuspended in $600 \mu \mathrm{l}$ of $\mathrm{OM}\left(1.2 \mathrm{M} \mathrm{MgSO}_{4}\right.$ in $10 \mathrm{mM} \mathrm{NaH}_{2} \mathrm{PO}_{4}$ adjusted to $\mathrm{pH} 5.8$ with $1 \mathrm{M} \mathrm{Na}_{2} \mathrm{HPO}_{4}$ ) and digested using $0.2 \mathrm{ml} / \mathrm{g}$ of mycelium of $\beta$-glucuronidase (Sigma-Aldrich, St. Louis) and $1 \mathrm{ml} / \mathrm{g}$ of lysing enzymes from Trichoderma harzianum (Sigma-Aldrich). After incubation on ice for $5 \mathrm{~min}$, $0.5 \mathrm{ml} / \mathrm{g}$ of bovine serum albumin $(12 \mathrm{mg} / \mathrm{ml})$ was added to the enzymatic mixture. Digestion was performed at $65 \mathrm{rpm}$ at $26^{\circ} \mathrm{C}$ and was stopped at $30 \mathrm{~min}, 1 \mathrm{~h}, 1 \mathrm{~h} 30 \mathrm{~min}, 2 \mathrm{~h} 30 \mathrm{~min}$, and $5 \mathrm{~h}$.
For each strain, three biological replicates were analyzed. The obtained spheroplasts were counted with a hemacytometer. Statistical analysis of significance was performed as described above.

\section{RESULTS}

Cpkk1 overexpressed and overexpressed-deletion mutants. For functional characterization of Cpkk1, we expressed the wildtype gene and a truncated version (lacking the entire catalytic domain of the protein and its carboxyl terminus) under the control
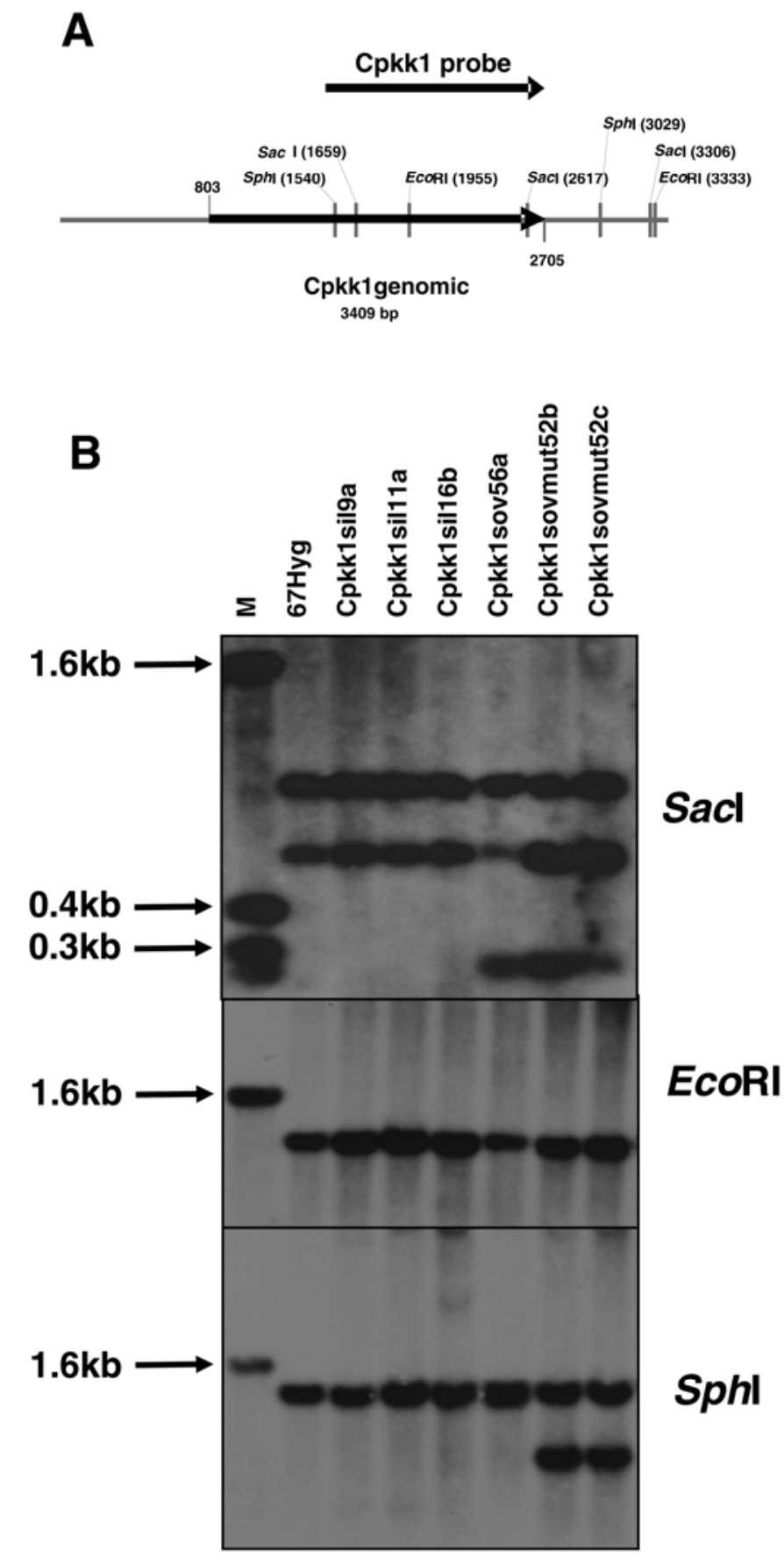

Fig. 3. A, Restriction map of $c p k k 1$ locus derived from sequence present in the database and schematic representation of the RNA probe used. B, Southern blot analysis of Cryphonectria parasitica genomic DNA digested with different restriction enzymes $S a c \mathrm{I}, E c o$ RI, and SphI. The complete name of the strain is reported for each lane. $\mathrm{M}=1-\mathrm{kb}$ ladder (Gibco BRL). Marker bands reacting with a tail in the riboprobe are indicated by arrows. Equal loading of total DNA was confirmed by ethidium bromide staining (not shown). 
of the cryparin promoter, which regulates the expression of an abundant Cryphonectria parasitica hydrophobin (68). We performed independent transformations of $C$. parasitica strain EP67 spheroplasts. The fungal spheroplasts were transformed with the vector pCrygenBam and the obtained fungal strain (named $67 \mathrm{Hyg}$ ) was used as positive control.

The transformants containing the overexpression vectors for the wild-type and truncated versions of Cpkk1 were selected first on PDAmb plates plus hygromycin $(50 \mathrm{mg} / \mathrm{liter})$. More than 100 transformants for each treatment were then screened by qRT-PCR (data not shown) and the mutants were selected that showed marked overexpression of the mRNA; these isolates were then single spored. All single-spored isolates were reanalyzed by qRTPCR to confirm the previous results. From the strains overexpressing Cpkk1, we chose one that we called Cpkk1sov56a and two strains overexpressing the truncated protein named Cpkk1sovmut52b and Cpkk1sovmut52c (Table 2).

Cpkk1-silenced mutants. Because a previous attempt to obtain cpkkl knock-out strains failed (61), we tried to obtain its specific mRNA silencing by the expression of an introduced hair-

TABLE 2. Cryphonectria parasitica mutants obtained in our study

\begin{tabular}{ll}
\hline C. parasitica mutations & Names of strains \\
\hline Positive control (mock) & 67Hyg \\
Cpkk1-overexpressed strain & Cpkk1sov56a \\
Cpkk1-overexpressed mutated strains & Cpkk1sovmut52b \\
& Cpkk1sovmut52c \\
Cpkk1-silenced strains & Cpkk1sil16b \\
& Cpkk1sil9a \\
& Cpkk1sil11a \\
\hline
\end{tabular}

pin RNA (Fig. 2B). We followed the same protocol for transformation and screening as described for the Cpkk1 overexpression strains. More than 100 transformants were screened by qRT-PCR; mutants in which silencing was most efficient were selected and the isolates were single spored and reanalyzed by qRT-PCR to confirm the previous results (not shown). From the silenced Cpkk1 strains, we choose three different transformants called Cpkk1sil16b, Cpkk1sil9a, and Cpkk1sil11a.

Southern and Northern blot analysis. Southern blot analysis with a hygromycin-derived probe confirmed the integration of the plasmids used for transformation into the $C$. parasitica genome (not shown). The wild-type locus of $c p k k l$ was unaffected by the transformation (Fig. 3). Digestion and hybridization with the synthesized riboprobe produced bands of the expected size: a band of 1,489 bp for $S p h$ I, the expected 1,378 bp and a much higher molecular weight band (not shown) for EcoRI, and two bands (689 and $958 \mathrm{bp}$ ) for $S a c \mathrm{I}$. The $1-\mathrm{kbp}$ band present in the digestion with SphI of Cpkk1sovmut52b and Cpkk1sovmut52c was derived solely from the transformation plasmid (with the deletion of $\approx 400 \mathrm{bp}$ of the truncated expression plasmid). The equal intensity of the bands (compared with the wild type) suggested a single insertion event. The same can be said for the 300-bp band in the SacI digestion also derived only from the transformation plasmid (see map derived from Fig. 1B).

The results of the mutational analysis of Cpkk1 (overexpression and silencing) were confirmed by Northern blot analysis using a specific probe for Cpkk1 (Fig. 4A); as expected, the size of the mRNA from the deletion mutants indicated a shorter transcript than from the wild-type strains. Furthermore, the size of the mRNA for the Cpkk1sov56a strain was slightly shorter than the wild-type, possibly because it was derived from the cryparin
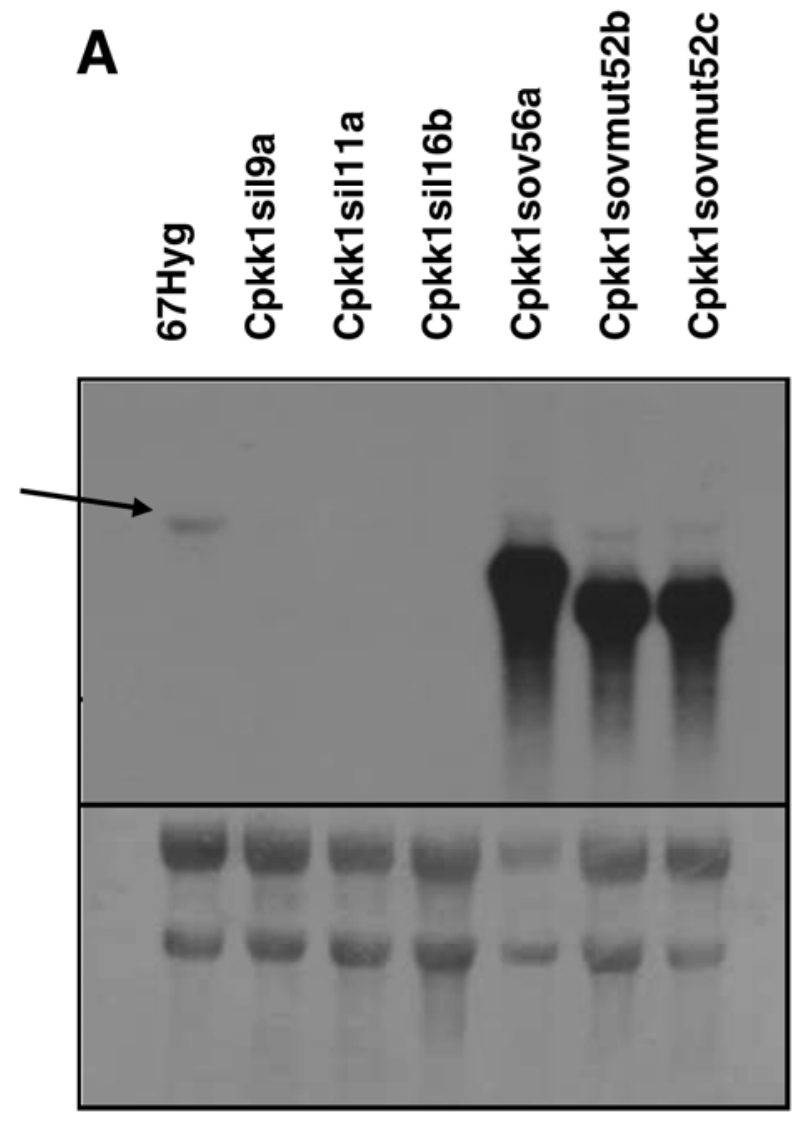

B

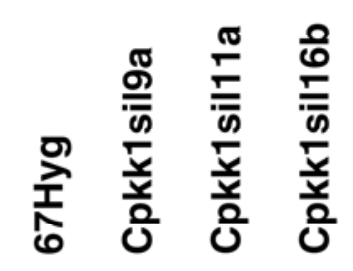

\section{Cpkk1 probe}

rRNA

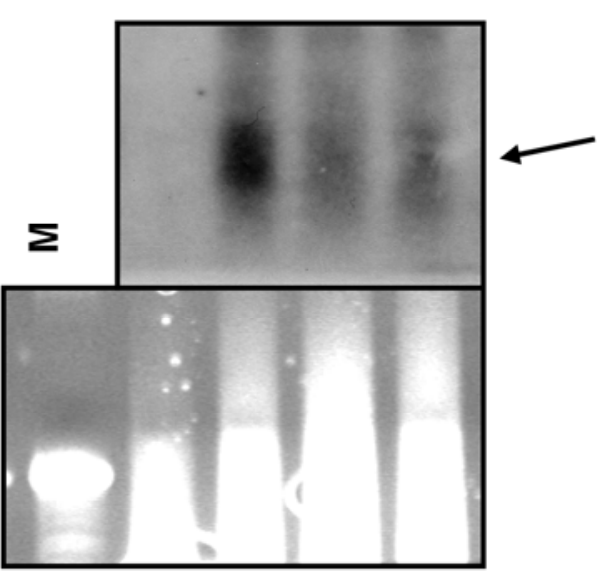

SIRNA

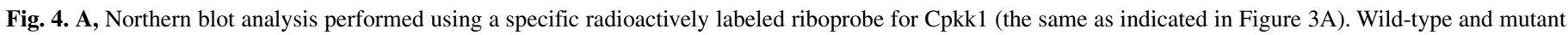

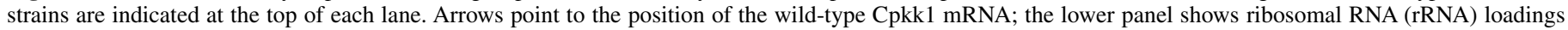

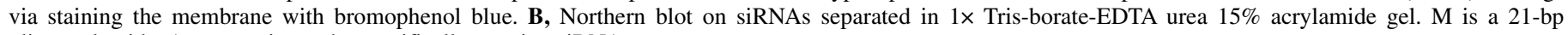
oligonucleotide. Arrows point to the specifically reacting siRNAs. 
promoter and terminator (therefore, it might have a shorter $5^{\prime}$ and $3^{\prime}$ untranslated region). The coding sequence was unaffected as judged by the size of the overexpressed protein on Western blot analysis (see below) (Fig. 5). It should be noted that, in the growth conditions tested here, the mRNA expression under control of the cryparin promoter was much more abundant than with the wild-type promoter.

Specific siRNAs hybridizing with the $c p k k l$ probe were present in the silenced strains, whereas this hybridization was absent in the 67Hyg control (Fig. 4B).

Western blot analysis. Western blot analysis was used to evaluate the levels of Cpkk1 protein accumulation in the mutated strains obtained (Fig. 5) using specific Cpkk1 antibodies. Both the quantity and quality of the protein extracts present in the gel can be visualized by Coomassie staining. Use of specific antibodies against Cpkk1 confirmed the results of the qRT-PCR for both the Cpkk1 overexpressed strain (Cpkk1sov56a) and the three Cpkk1 silenced strains (Cpkk1sil16b, Cpkk1sil9a, and Cpkk1sil11a). In the two strains overexpressing a deleted form of Cpkk1 (Cpkk1sovmut52b and Cpkk1sovmut52c), the antibodies recognized the wild-type form of the protein (putative molecular mass $[\mathrm{MM}] 57 \mathrm{kDa})(61)$ and the truncated form of Cpkk1 (estimated MM $29 \mathrm{kDa}$ ).

Evaluation of growth on different media and conidial sporulation. The selected mutated strains for Cpkk1 were evaluated for their growth on different solid media, particularly on PDAmb and EP minimal (Table 3). Colony diameter on PDAmb at 5 dpi was larger for the strains Cpkk1sov56a and Cpkk1sovmut52c than for
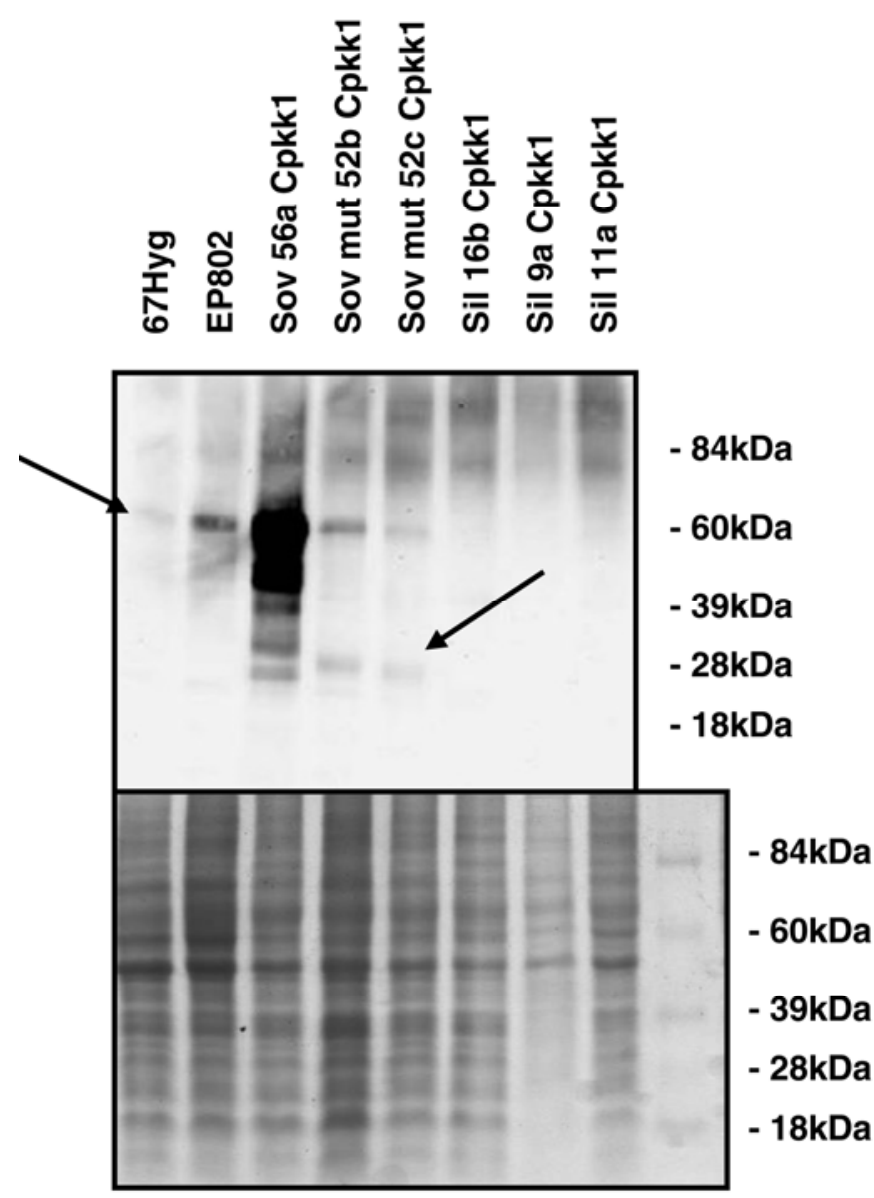

Fig. 5. Western blot analysis using specific antibodies against Cpkk1 diluted 1:2000. Coomassie staining of the gel estimates the protein concentration. Reaction of the protein extract was evaluated against Cpkk1 antibodies. Names of the strains used in the experiment are reported for each lane. Arrows point to the wild-type and truncated forms of Cpkk1. Protein molecular mass markers are reported. the wild type (Supplementary Figure 1) and these differences were statistically significant. Silencing of the $c p k k l$ gene was not observed to reduce colony diameter on PDAmb, whereas a statistically significant reduction in colony diameter was noted for the Cpkk1 overexpressed mutated strain (Cpkk1sovmut52c) and for the two Cpkk1-silenced strains (Cpkk1sil16b and Cpkk1sil11a) on EP minimal (Supplementary Figure 1).

The results of conidial sporulation are illustrated in Table 4; Tukey's HSD test showed a significant decrease in conidia production only for the silenced strain Cpkk1sil16b.

Pathogenicity tests. Three-year-old European chestnut fruit were inoculated with mutated strains for Cpkk1. The canker area was measured every 2 weeks beginning 30 dpi and was approximated to an ellipse (51). The differences between the canker area generated by the mutated strains and the control were transformed logarithmically and then analyzed using the two-way ANOVA. Results are reported in Table 5 and a graphic rendition is given in Figure 6. Mutations of Cpkk1 had a strong effect on virulence; the canker area for strains Cpkk1sovmut52b and the three silenced Cpkk1 strains were significantly smaller than those for the positive control 67Hyg. Virulence assay on Golden Delicious apple fruit confirmed the results of the virulence test on Castanea sativa trees. In this second virulence test, apple fruit were inoculated with a 7-day-old mycelium of the Cpkk1- overexpressing and silenced strains. Strain $67 \mathrm{Hyg}$ and PDAmb-only treatments were also included as controls. The difference in lesion size on the apple fruit caused by the Cpkk1sov56a, Cpkk1sovmut52c, and two Cpkk1-silenced strains (Cpkk1sil16b and Cpkk1sil11a) was statistically significant (Table 6; Supplementary Figure 2).

Resistance to cell-wall-degrading enzymes. In our experiments, young mycelia were well digested with the lytic enzyme mixture for the four fungal strains tested, except for strain Cpkk1sil11a: its digestion resulted in the production of significantly fewer spheroplasts (Table 7).

TABLE 3. Effect of mutational analysis of Cpkk1 on growth on potato dextrose agar containing methionine and biotin (PDAmb) and EP minimal plates $^{\mathrm{y}}$

\begin{tabular}{lccccc}
\hline & \multicolumn{2}{c}{ PDAmb plates } & & \multicolumn{2}{c}{ EP minimal plates } \\
\cline { 2 - 3 } \cline { 5 - 6 } Fungal strains & Diameter $(\mathrm{cm})^{\mathrm{z}}$ & $\pm \mathrm{SD}$ & & Diameter $(\mathrm{cm})$ & $\pm \mathrm{SD}$ \\
\hline 67Hyg & $5.6 \mathrm{a}$ & 0.2 & & $5.9 \mathrm{e}$ & 0.1 \\
Cpkk1sov56a & $6.8 \mathrm{~cd}$ & 0.2 & & $6.0 \mathrm{e}$ & 0.2 \\
Cpkk1sovmut52b & $6.2 \mathrm{abc}$ & 0.2 & & $5.7 \mathrm{de}$ & 0.2 \\
Cpkk1sovmut52c & $6.4 \mathrm{~cd}$ & 0.4 & & $5.5 \mathrm{~cd}$ & 0.1 \\
Cpkk1sil16b & $5.7 \mathrm{ab}$ & 0.2 & & $4.6 \mathrm{a}$ & 0.1 \\
Cpkk1sil11a & $5.6 \mathrm{a}$ & 0.2 & & $5.1 \mathrm{bc}$ & 0.1 \\
\hline
\end{tabular}

y Statistical analysis was performed using one-way analysis of variance. SD = standard deviation; values within a column followed by the same letter are not significantly different according to Tukey's test $(P<0.05)$.

${ }^{\mathrm{z}}$ Colony diameter evaluation was made 5 days postinoculation.

TABLE 4. Effect of mutational analysis of Cpkk1 on asexual spores production on potato dextrose agar containing methionine and biotin plates ${ }^{\mathrm{x}}$

\begin{tabular}{lll}
\hline Fungal strains & Spores/mly & $\pm \mathrm{SD}^{\mathrm{z}}$ \\
\hline 67Hyg & $8.00 \mathrm{E}+07 \mathrm{~b}$ & $6.79 \mathrm{E}+07$ \\
Cpkk1sov56a & $6.40 \mathrm{E}+07 \mathrm{~b}$ & $4.53 \mathrm{E}+07$ \\
Cpkk1sovmut52b & $8.80 \mathrm{E}+07 \mathrm{~b}$ & $1.13 \mathrm{E}+07$ \\
Cpkk1sovmut52c & $3.20 \mathrm{E}+07 \mathrm{ab}$ & $2.26 \mathrm{E}+07$ \\
Cpkk1sil16b & $6.40 \mathrm{E}+06 \mathrm{a}$ & $4.53 \mathrm{E}+06$ \\
Cpkk1sil11a & $1.20 \mathrm{E}+07 \mathrm{ab}$ & $1.13 \mathrm{E}+06$ \\
\hline
\end{tabular}

${ }^{x}$ Statistical analysis was performed using one-way analysis of variance. Values followed by the same letter are not significantly different according to Tukey's highly significant difference test $(P<0.05)$.

y Values were transformed logarithmically for analysis of variance and separation of means but actual values are reported.

z $\mathrm{SD}=$ standard deviation. 


\section{DISCUSSION}

There are many possible approaches to functional characterization of a protein. Because a previous attempt to obtain knockout strains for Cpkk1 failed (61), we attempted to induce PTGS for the cpkkl gene as an alternative method to analyze the function of an essential gene (45). This approach has been successfully applied to Cryphonectria parasitica before $(23,28,56)$.

We also decided to overexpress the wild-type protein of interest to evaluate the consequences at the phenotypic, physiological, and molecular levels. This approach has also been used for other $C$. parasitica genes $(14,32)$. The third prong of our strategy involved creating a mutant strain with a truncation in the catalytic domain of the protein so as to obtain a putative negative dominant allele after the deleted gene was introduced in the $C$. parasitica genome. This method has been reported for other fungi, including Candida albicans (36), Saccharomyces cerevisiae (39), and Aspergillus nidulans (62), as an alternative in the study of the functions of lethal genes (36) but it has not been attempted yet for Cryphonectria parasitica. Our choice to use the developmentally regulated cryparin promoter (instead of a constitutive one, as commonly used in $C$. parasitica transgene expression) stems from the attempt to avoid potential drastic effects on the growth of a Cpkk1 knock-out that could be inferred as being likely from published data and from our failure to produce a viable knock-out strain (61).

In the yeast $S$. cerevisiae, MAPKs are involved in five distinct pathways: mating response, filamentous growth, cell wall integrity, high osmolarity growth, and ascospore formation (26). The Cpkk1 sequence is most homologous with members of the serine/threonine tyrosine dual-specificity protein kinase family. In particular, the catalytic domain (in the C-terminal half-part of the protein) has shown the highest similarity with $S$. cerevisiae Mkk1 and Mkk2, two MEK proteins involved in the yeast cell wall integrity pathway (61). Although the sequence homology between Cpkk1 Cpkk2, and Cpkk3 and the S. cerevisiae MAPKKs (Mkk1/Mkk2, Ste7, and Pbs2) has been demonstrated by phylogenetic analysis $(52,61)$, we do not know whether the homologous MAPKKs of $C$. parasitica play the same roles. In fact, it has been reported that the pheromone-induced signal transduction pathway in two evolutionarily distinct yeasts, $S$. cerevisiae and Schizosaccharomyces pombe, is conserved, and that the proteins involved have the same functions (Ste11/byr2, Ste7/byr1, and Fus3/spk1) (46). However, the HOG pathway in $S$. pombe controls responses to a wider spectrum of environmental stresses (e.g., oxidative stress, UV exposure, and heat shock) than the HOG pathway in Saccharomyces cerevisiae (8), indicating a diverging function of molecular homologues in closely related species. A recent work comparing the function of the components of the Pmk1p/Fus3p MAPK signal transduction pathway in Magnaporthe grisea and Mycosphaerella graminicola showed that the expression of genes affected by the Ste12 homologue transcription factor were instead conserved (35).

When comparison is extended to filamentous fungi, less is known about the overall conservation of function among homologues of the MAPK cascades. For example, only three of the five basic MAPK modules identified in yeast so far have been identified in the filamentous ascomycetes $N$. crassa, Magnaporthe grisea, and A. nidulans.

Our knowledge of the third MAPK pathway (cell wall integrity) in filamentous fungi is still limited, even if mutants in the MAPK homologous to yeast Slt2 have been generated in A. nidulans and in several phytopathogenic fungi $(9,27,34,42,65)$. Common phenotypes of Slt2-like kinase mutants include altered cell walls and defects in conidial germination (which could be remediated by high osmolarity media) and autolysis in the central area of the colony, suggesting the involvement of a cell integrity-type MAPK pathway in filamentous fungi (38). It has recently been demonstrated that the nine components of the three MAPK modules of $N$. crassa act as three distinct modules during vegetative growth and asexual development; however, joint activity of the three pathways is required for hyphal fusion and formation of more complex multicellular structures necessary to undergo sexual development (38).

In our study, we obtained some mutant strains that overexpress the Cpkk1 protein and other strains silenced for the same gene. For this protein, we also obtained a putative dominant negative allele. We evaluated these mutated strains for different biological properties and their virulence on European chestnut, Castanea sativa, in particular. We observed a marked reduction in canker area generated by Cpkk1 mutated strains on $C$. sativa which was statistically significant for the three silenced Cpkk1 strains (Cpkk1sil16b, -9a, and -11a) and for the strain overexpressing the truncated form of the protein (Cpkk1sovmut52b), whereas overexpressing a wild-type allele of the Cpkk1 protein apparently had no effect on the phenotype. The silencing and the creation of a dominant negative allele for Cpkk1 showed that Cpkk1 is an important component in the expression of virulence for Cryphonectria parasitica.

The involvement of MAPK in fungal pathogenesis has been reviewed in detail $(63,70)$ and has been demonstrated for many phytopathogenic fungi. In the filamentous fungus $M$. grisea, for example, the three MAPKs in the FUS3/KSS1 pathway and the three in the SLT2 pathway have been cloned and characterized and all found to be involved in fungal pathogenesis $(64,69)$.

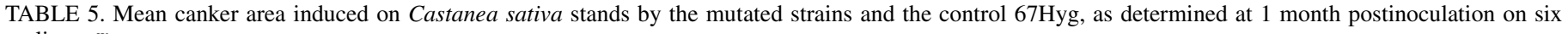
replicates ${ }^{\mathrm{w}}$

\begin{tabular}{|c|c|c|c|c|c|}
\hline C. parasitica strains & Mean canker area $\left(\mathrm{cm}^{2}\right)^{\mathrm{x}}$ & $\pm \mathrm{SD}^{\mathrm{y}}$ & Plant & $P$ for plants $(95 \%)$ & $P$ for strains $(95 \%)^{\mathrm{z}}$ \\
\hline 67Hyg & 4.42 & 2.82 & $1-2-13$ & 0.126 & 0.247 \\
\hline Cpkk1sov56a & 2.53 & 0.99 & $\ldots$ & $\ldots$ & $\ldots$ \\
\hline $67 \mathrm{Hyg}$ & 5.48 & 2.05 & $3-4-14$ & 0.778 & $0.001 *$ \\
\hline Cpkk1sovmut52b & 0.89 & 0.40 & $\ldots$ & $\ldots$ & $\ldots$ \\
\hline $67 \mathrm{Hyg}$ & 10.31 & 16.18 & $5-6-15$ & 0.063 & 0.058 \\
\hline Cpkk1sovmut52c & 2.37 & 1.67 & $\ldots$ & $\ldots$ & $\ldots$ \\
\hline 67Hyg & 14.64 & 14.76 & $7-8-16$ & 0.097 & $0.001 *$ \\
\hline Cpkk1sil16b & 0.73 & 0.22 & $\ldots$ & $\ldots$ & $\ldots$ \\
\hline 67Hyg & 4.24 & 1.52 & $9-10-17$ & 0.836 & $0.0049^{*}$ \\
\hline Cpkk1sil9a & 1.72 & 1.26 & $\cdots$ & $\ldots$ & $\ldots$ \\
\hline $67 \mathrm{Hyg}$ & 4.21 & 1.98 & $11-12-18$ & 0.921 & $0.001 *$ \\
\hline Cpkk1sil11a & 0.61 & 0.28 & $\ldots$ & $\ldots$ & $\ldots$ \\
\hline
\end{tabular}

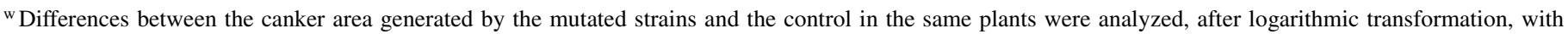
two-way analysis of variance to test for influence of the individual plant.

${ }^{x}$ Canker area was calculated using the formula for an ellipse and the area of the original wound was not subtracted from the final measurements.

y $\mathrm{SD}=$ standard deviation.

z Values followed by an asterisk are significantly different $(P<0.05)$. 
In U. maydis, the three modules (including MAPK Kpp2 and Kpp6, MAPKK Fuz7, and MAPKKK Kpp4 belonging to the FUS3/KSS1 pathway) are required for transcriptional response to pheromones, filamentous growth, mating, and pathogenicity $(6,7,29,44)$. MGV1, the $F$. graminearum Slt2 homologue, is required for female fertility, heterokaryon formation, and plant infection (27). They are not common phenotypes for Slt2like kinase mutants, which typically display altered cell walls, defects in conidial germination (which could be remediated by high osmolarity media), and autolysis in central areas of the colony (38).

Previous to this report, no MAPK member of the cell wall integrity pathway has been characterized in $C$. parasitica. For this fungus, the deletion of CpMK2, homolog to FUS3/KSS1 of $S$. cerevisiae, induces a lower growth rate and reduced canker size (probably as an indirect effect of growth reduction) and the mutants are defective in conidiation and pheromone production (12). Another MAPK of C. parasitica, Cpmk1 (a homolog to

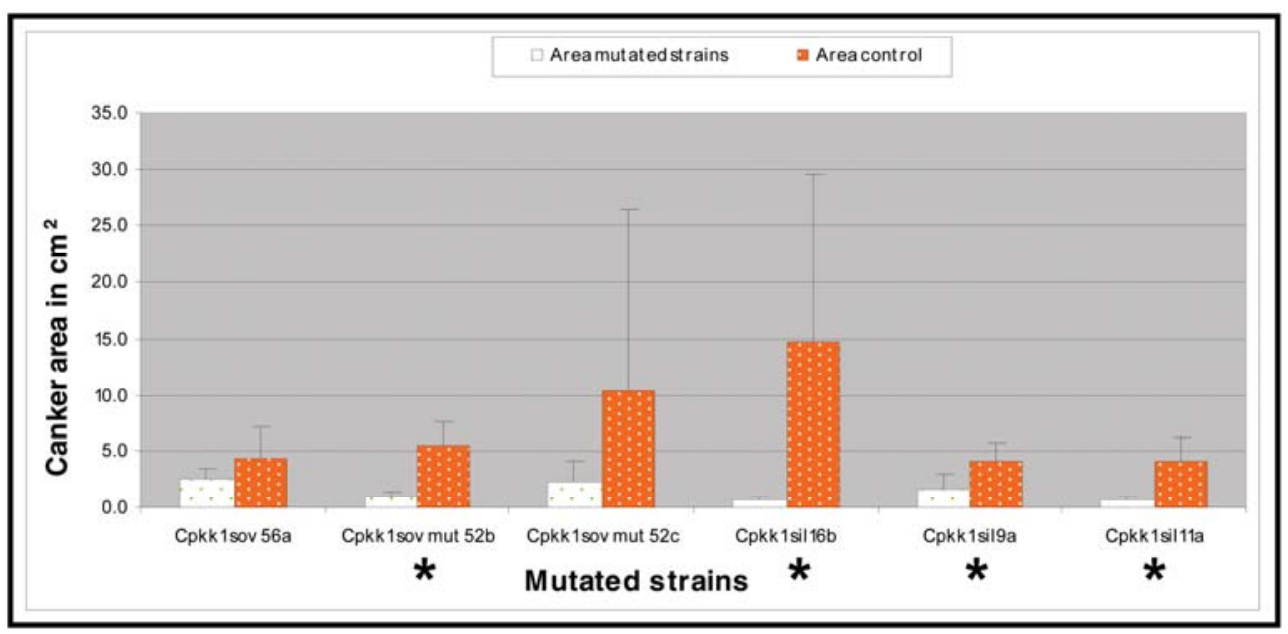

A

B

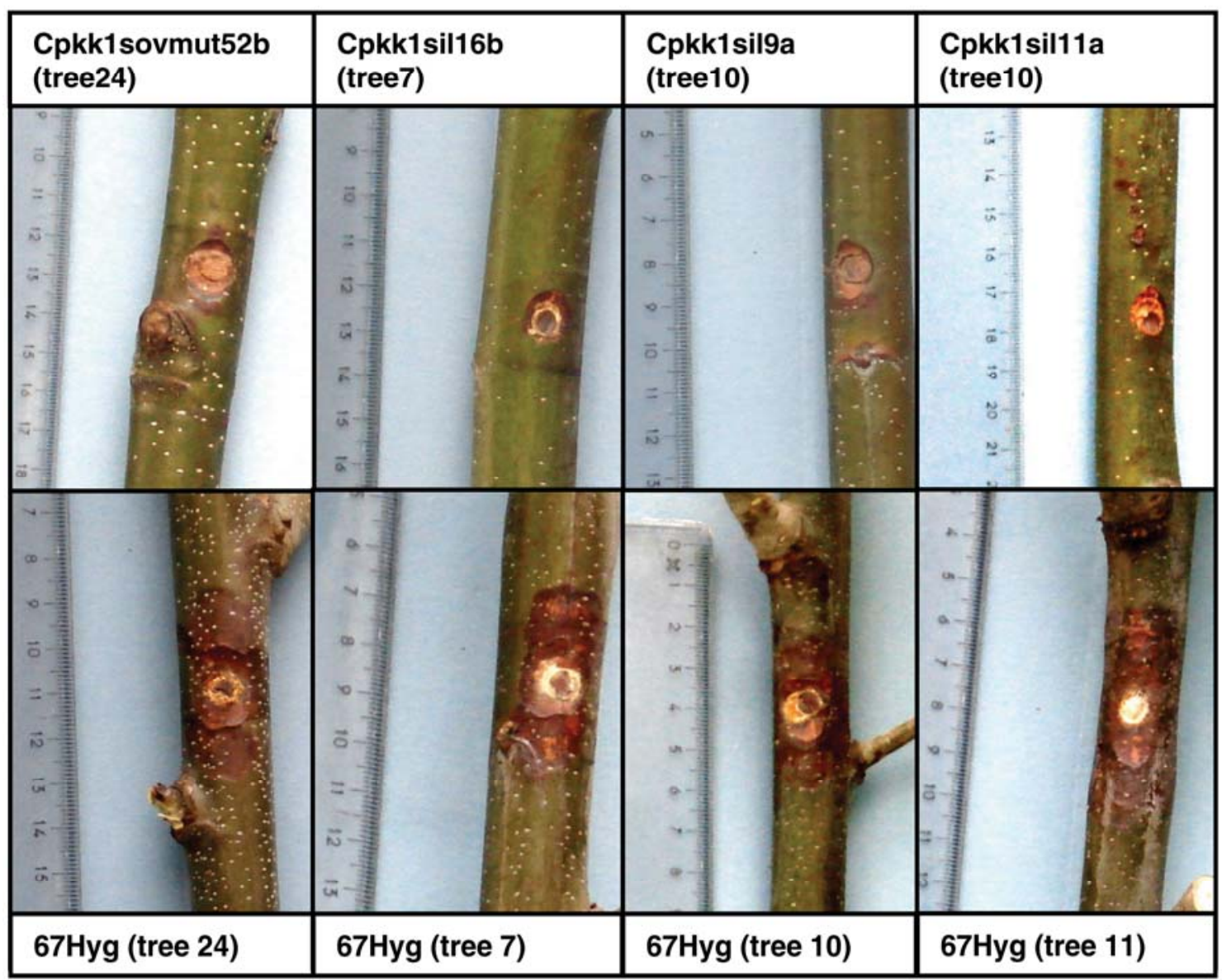

Fig. 6. A, Diagrams of the virulence assays performed on Castanea sativa; the experiments marked by an asterisk are significantly different $(P<0.05)$. Error bars represent the values of the standard deviation. B, Photographs of the same virulence assays of a selection of the Cpkk1 mutants on 3-year-old C. sativa stands, 1 month after inoculation. 
TABLE 6. Mean canker area induced on Golden Delicious apple fruit by the mutated strains and the control EP67, as measured at 5 days postinoculation on six replicates ${ }^{x}$

\begin{tabular}{lcc}
\hline Fungal strains & Mean canker area $\left(\mathrm{cm}^{2}\right)^{\mathrm{y}}$ & $\pm \mathrm{SD}^{\mathrm{z}}$ \\
\hline 67Hyg & $6.8 \mathrm{~d}$ & 0.2 \\
Cpkk1sovmut56a & $5.5 \mathrm{bc}$ & 0.5 \\
Cpkk1sov mut52b & $4.5 \mathrm{~b}$ & 0.3 \\
Cpkk1sov mut52c & $6.4 \mathrm{~cd}$ & 1.2 \\
Cpkk1sil16b & $0.5 \mathrm{a}$ & 0.0 \\
Cpkk1sil11a & $0.5 \mathrm{a}$ & 0.0 \\
PDAmb & $0.5 \mathrm{a}$ & 0.0 \\
\hline
\end{tabular}

${ }^{x}$ Differences between the canker area generated by the mutated strains and the control EP67 were analyzed using one-way analysis of variance. Values followed by the same letter are not significantly different according to Tukey's highly significant difference test $(P<0.05)$.

${ }^{y}$ Canker area was calculated using the formula for a circle and the area of the original wound was not subtracted from the final measurements.

${ }^{\mathrm{z}} \mathrm{SD}=$ standard deviation.

HOG1), has been shown to be involved in fungal pathogenesis (48), whereas Osm1 in $M$. grisea is dispensable for plant infection (21). These differences clearly explain that, although signal transduction pathways components may be phylogenetically conserved, the biological function of the corresponding components may be quite dissimilar (48).

A recent review has underlined the different roles of each of the three MAPK pathways in the pathogenesis of fungi and in the interaction with different hosts (70). In general, the Fus3/Kss 1 pathway is essential for regulation of plant infection processes (69), whereas the homologues of Fus3/Kss1, Ste7, and Ste11 in the basidiomycete Cryptococcus neoformans are required only for mating and cell-type-specific differentiation but do not play important roles in virulence (16).

The cell wall integrity pathway is important for pathogenesis and during plant infection in particular, as shown for $M$. grisea (65), Colletotrichum lagenarium (34), Claviceps purpurea (42), $F$. graminearum (27,50), Mycosphaerella graminicola (41), and $B$. cinerea (53). Our study is the first to provide evidence for the involvement of the cell wall integrity pathway for Cryphonectria parasitica.

Our attempt at showing the role of Cpkk1 through various mutagenesis approaches could only unmask the specific role of Cpkk1 in fungal pathogenesis and, to a lesser extent, reveal its role in growth in minimal media and conidia production on PDAmb. Other aspects of fungal morphogenesis and life cycle did not seem to be strongly affected. Our results somewhat contradict those from previous studies in which the knock-out method was applied to other fungi and, for instance, a much clearer role of the Cpkk1 homologue in N. crassa (Mek1) was shown. The differences could be due to the fact that silencing might have only a quantitative effect on reducing the amount of functional protein, thus allowing the completion of some of its physiological functions. Another possible explanation is that the cryparin promoter used for the expression of the hairpin and the protein overexpression is inactive in the early phases of mycelial growth (cryparin cannot be detected during the first $24 \mathrm{~h}$ after inoculation of liquid media with conidia) but becomes active only in later developmental phases. Such a delay probably allows normal expression of the MEKKs studied in the early growth phases, which permitted us to monitor the effect of their mutagenesis only in the later developmental phases.

Overall, the use of silencing techniques versus knock-out techniques to study gene function might result in different outcomes (i.e., when a gene's complete functional disruption has a strong impact on growth) and delayed silencing (as in our work) might reveal the gene's secondary (more subtle) effects. Nevertheless, when possible, both approaches may be recommended because they can complement each other in revealing the functional characterization of a gene.
TABLE 7. Number of spheroplasts produced after digestion of the cell wall of several mutants with specific enzymes starting from the same amount of mycelia as measured by weight ${ }^{\mathrm{x}}$

\begin{tabular}{lcc}
\hline Fungal strains & Spheroplasts $/ \mathrm{ml}^{\mathrm{y}}$ & $\pm \mathrm{SD}^{\mathrm{z}}$ \\
\hline $67 \mathrm{Hyg}$ & $2.19 \mathrm{E}+07 \mathrm{~b}$ & $8.93 \mathrm{E}+06$ \\
Cpkk1sil16b & $1.76 \mathrm{E}+07 \mathrm{~b}$ & $7.19 \mathrm{E}+06$ \\
Cpkk1sil11a & $3.38 \mathrm{E}+06 \mathrm{a}$ & $1.38 \mathrm{E}+06$ \\
\hline
\end{tabular}

x Statistical analysis was performed using one-way analysis of variance. Values followed by the same letter are not significantly different according to Tukey's highly significant difference test $(P<0.05)$.

y Values were transformed logarithmically for analysis of variance and separation of the means, but actual values are reported.

${ }^{\mathrm{z}} \mathrm{SD}=$ standard deviation

\section{ACKNOWLEDGMENTS}

We thank J. C. Scott for editing the manuscript and P. Caciagli for help with the statistical analysis.

\section{LITERATURE CITED}

1. Allen, T. D., Dawe, A. L., and Nuss, D. L. 2003. Use of cDNA microarrays to monitor transcriptional responses of the chestnut blight fungus Cryphonectria parasitica to infection by virulence-attenuating hypoviruses. Eukaryot. Cell 2:1253-1265.

2. Allen, T. D., and Nuss, D. L. 2004. Specific and common alterations in host gene transcript accumulation following infection of the chestnut blight fungus by mild and severe hypoviruses. J. Virol. 78:4145-4155.

3. Alonso-Monge, R., Navarro-Garcia, F., Molero, G., Diez-Orejas, R., Gustin, M., Pla, J., Sanchez, M., and Nombela, C. 1999. Role of the mitogen-activated protein kinase hog $1 \mathrm{p}$ in morphogenesis and virulence of Candida albicans. J. Bacteriol. 181:3058-3068.

4. Anagnostakis, S. L. 1977. Vegetative incompatibility in Endothia parasitica. Exp. Mycol. 1:306-316.

5. Anagnostakis, S. L. 1982. Biological control of Chestnut blight. Science 215:466-471.

6. Andrews, D. L., Egan, J. D., Mayorga, M. E., and Gold, S. E. 2000. The Ustilago maydis ubc4 and ubc5 genes encode members of a MAP kinase cascade required for filamentous growth. Mol. Plant-Microbe Interact. 13:781-786.

7. Banuett, F., and Herskowitz, I. 1994. Identification of Fuz7, A Ustilago maydis Mek/Mapkk homolog required for a-locus-dependent and a-locusindependent steps in the fungal life-cycle. Genes Dev. 8:1367-1378.

8. Brewster, J. L., and Gustin, M. C. 1994. Positioning of cell-growth and division after osmotic-stress requires a map kinase pathway. Yeast 10:425439.

9. Bussink, H. J., and Osmani, S. A. 1999. A mitogen-activated protein kinase (MPKA) is involved in polarized growth in the filamentous fungus, Aspergillus nidulans. FEMS Microbiol. Lett. 173:117-125.

10. Carroll, A. M., Sweigard, J. A., and Valent, B. 1994. Improved vectors for selecting resistance to hygromycin. Fungal Genet. Newsl. 41:22.

11. Chen, B. S., Gao, S. J., Choi, G. H., and Nuss, D. L. 1996. Extensive alteration of fungal gene transcript accumulation and elevation of Gprotein-regulated cAMP levels by a virulence-attenuating hypovirus. Proc. Natl. Acad Sci. USA 93:7996-8000.

12. Choi, E. S., Chung, H. J., Kim, M. J., Park, S. M., Cha, B. J., Yang, M. S., and Kim, D. H. 2005. Characterization of the ERK homologue CpMK2 from the chestnut blight fungus Cryphonectria parasitica. Microbiology 151:1349-1358.

13. Choi, G. H., Chen, B. S., and Nuss, D. L. 1995. Virus-mediated or transgenic suppression of a g-protein alpha-subunit and attenuation of fungal virulence. Proc. Natl. Acad. Sci. USA 92:305-309.

14. Choi, G. H., Pawlyk, D. M., Rae, B., Shapira, R., and Nuss, D. L. 1993. Molecular analysis and overexpression of the gene encoding endothiapepsin, an aspartic protease from Cryphonectria parasitica. Gene 125:135-141.

15. Churchill, A. C. L., Ciuffetti, L. M., Hansen, D. R., Vanetten, H. D., and Van Alfen, N. K. 1990. Transformation of the fungal pathogen Cryphonectria parasitica with a variety of heterologous plasmids. Curr. Genet. 17:25-31.

16. Clarke, D. L., Woodlee, G. L., McClelland, C. M., Seymour, T. S., and Wickes, B. L. 2001. The Cryptococcus neoformans STE11 alpha gene is similar to other fungal mitogen-activated protein kinase kinase kinase (MAPKKK) genes but is mating type specific. Mol. Microbiol. 40:200213.

17. Csank, C., Schroppel, K., Leberer, E., Harcus, D., Mohamed, O., 
Meloche, S., Thomas, D. Y., and Whiteway, M. 1998. Roles of the Candida albicans mitogen-activated protein kinase homolog, Cek1p, in hyphal development and systemic candidiasis. Infect. Immun. 66:27132721.

18. Dawe, A. L., and Nuss, D. L. 2001. Hypoviruses and chestnut blight: exploiting viruses to understand and modulate fungal pathogenesis. Annu. Rev. Genet. 35:1-29.

19. Dawe, A. L., Segers, G. C., Allen, T. D., McMains, V. C., and Nuss, D. L. 2004. Microarray analysis of Cryphonectria parasitica $\mathrm{G}$ alpha- and $\mathrm{G}$ beta gamma-signalling pathways reveals extensive modulation by hypovirus infection. Microbiology 150:4033-4043.

20. Di Pietro, A., Garcia-Maceira, F. I., Meglecz, E., and Roncero, M. I. G. 2001. A MAP kinase of the vascular wilt fungus Fusarium oxysporum is essential for root penetration and pathogenesis. Mol. Microbiol. 39:11401152.

21. Dixon, K. P., Xu, J. R., Smirnoff, N., and Talbot, N. J. 1999. Independent signaling pathways regulate cellular turgor during hyperosmotic stress and appressorium-mediated plant infection by Magnaporthe grisea. Plant Cell 11:2045-2058.

22. Elliston, J. E. 1985. Characterisation of dsRNA-free and dsRNAcontaining strains of Endothia parasitica in relation to hypovirulence. Phytopathology 75:151-158.

23. Gullusci, M., and Turina, M. 2007. Silencing of cryparin, a cell wall hydrophobin, in Cryphonectria parasitica. J. Plant Pathol. 89:141-147.

24. Gustin, M. C., Albertyn, J., Alexander, M., and Davenport, K. 1998. MAP kinase pathways in the yeast Saccharomyces cerevisiae. Microbiol. Mol. Biol. Rev. 62:1264-1300.

25. Hepting, G. H. 1974. Death of the American chestnut. J. For. Hist. 18:6067.

26. Herskowitz, I. 1995. Map kinase pathways in yeast-for mating and more. Cell 80:187-197.

27. Hou, Z. M., Xue, C. Y., Peng, Y. L., Katan, T., Kistler, H. C., and Xu, J. R. 2002. A mitogen-activated protein kinase gene (MGV1) in Fusarium graminearum is required for female fertility, heterokaryon formation, and plant infection. Mol. Plant-Microbe Interact. 15:1119-1127.

28. Jacob-Wilk, D., Turina, M., Kazmierczak, P., and Van Alfen, N. K. 2009. Silencing of Kex2 significantly diminishes the virulence of Cryphonectria parasitica. Mol. Plant-Microbe Interact. 22:211-221.

29. Kahmann, R., and Kamper, J. 2004. Ustilago maydis: how its biology relates to pathogenic development. New Phytol. 164:31-42.

30. Kasahara, S., and Nuss, D. L. 1997. Targeted disruption of a fungal Gprotein beta subunit gene results in increased vegetative growth but reduced virulence. Mol. Plant-Microbe Interact. 10:984-993.

31. Kasahara, S., Wang, P., and Nuss, D. L. 2000. Identification of bdm-1, a gene involved in $\mathrm{G}$ protein beta-subunit function and alpha-subunit accumulation. Proc. Natl. Acad. Sci. USA 97:412-417.

32. Kim, M. J., Choi, J. W., Park, S. M., Cha, B. J., Yang, M. S., and Kim, D. H. 2002. Characterization of a fungal protein kinase from Cryphonectria parasitica and its transcriptional upregulation by hypovirus. Mol. Microbiol. 45:933-941.

33. Kim, M. J., Park, S. M., Kim, Y. H., Cha, B. J., Yang, M. S., and Kim, D. H. 2004. Deletion of a hypoviral-regulated cppk1 gene in a chestnut blight fungus, Cryphonectria parasitica, results in microcolonies. Fungal Genet. Biol. 41:482-492.

34. Kojima, K., Kikuchi, T., Takano, Y., Oshiro, E., and Okuno, T. 2002. The mitogen-activated protein kinase gene MAF1 is essential for the early differentiation phase of appressorium formation in Colletotrichum lagenarium. Mol. Plant-Microbe Interact. 15:1268-1276.

35. Kramer, B., Thines, E., and Foster, A. J. 2009. MAP kinase signalling pathway components and targets conserved between the distantly related plant pathogenic fungi Mycosphaerella graminicola and Magnaporthe grisea. Fungal Genet. Biol. 46:667-681.

36. Lee, S. A., Mao, Y. X., Zhang, Z. M., and Wong, B. 2001. Overexpression of a dominant-negative allele of YPT1 inhibits growth and aspartyl protease secretion in Candida albicans. Microbiology 147:1961-1970.

37. Lev, S., Sharon, A., Hadar, R., Ma, H., and Horwitz, B. A. 1999. A mitogen-activated protein kinase of the corn leaf pathogen Cochliobolus heterostrophus is involved in conidiation, appressorium formation, and pathogenicity: diverse roles for mitogen-activated protein kinase homologs in foliar pathogens. Proc. Natl. Acad. Sci. USA 96:13542-13547.

38. Maerz, S., Ziv, C., Vogt, N., Helmstaedt, K., Cohen, N., Gorovits, R., Yarden, O., and Seiler, S. 2008. The nuclear Dbf2-related kinase COT1 and the mitogen-activated protein kinases MAK1 and MAK2 genetically interact to regulate filamentous growth, hyphal fusion and sexual development in neurospora crassa. Genetics 179:1313-1325.

39. Mao, Y. X., Kalb, V. F., and Wong, B. 1999. Overexpression of a dominant-negative allele of SEC4 inhibits growth and protein secretion in Candida albicans. J. Bacteriol. 181:7235-7242.

40. McCabe, P. M., and Van Alfen, N. K. 2001. Molecular basis of symptom expression by the Cryphonectria hypovirus. Pages 125-144 in: dsRNA
Genetic Elements: Concepts and Applications. CRC Press, Boca Raton, FL.

41. Mehrabi, R., van der Lee, T., Waalwijk, C., and Kema, G. H. J. 2006. MgSlt2, a cellular integrity MAP kinase gene of the fungal wheat pathogen Mycosphaerella graminicola, is dispensable for penetration but essential for invasive growth. Mol. Plant-Microbe Interact. 19:389-398.

42. Mey, G., Held, K., Scheffer, J., Tenberge, K. B., and Tudzynski, P. 2002. CPMK2, an SLT2-homologous mitogen-activated protein (MAP) kinase, is essential for pathogenesis of Claviceps purpurea on rye: evidence for a second conserved pathogenesis-related MAP kinase cascade in phytopathogenic fungi. Mol. Microbiol. 46:305-318.

43. Muller, P., Aichinger, C., Feldbrugge, M., and Kahmann, R. 1999. The MAP kinase Kpp2 regulates mating and pathogenic development in Ustilago maydis. Mol. Microbiol. 34:1007-1017.

44. Muller, P., Weinzierl, G., Brachmann, A., Feldbrugge, M., and Kahmann, R. 2003. Mating and pathogenic development of the smut fungus Ustilago maydis are regulated by one mitogen-activated protein kinase cascade. Eukaryot. Cell 2:1187-1199.

45. Nakayashiki, H., Hanada, S., Quoc, N. B., Kadotani, N., Tosa, Y., and Mayama, S. 2005. RNA silencing as a tool for exploring gene function in ascomycete fungi. Fungal Genet. Biol. 42:275-283.

46. Neiman, A. M., Stevenson, B. J., Xu, H. P., Sprague, G. F., Herskowitz, I., Wigler, M., and Marcus, S. 1993. Functional homology of protein-kinases required for sexual-differentiation in schizosaccharomyces-pombe and Saccharomyces cerevisiae suggests a conserved signal transduction module in eukaryotic organisms. Mol. Biol. Cell 4:107-120.

47. Nuss, D. L., Chen, B., Geletka, L. M., Parsley, T. B., and Suzuki, N. 2001. Engineering hypoviruses for fundamental and practical applications. Pages 145-163 in: dsRNA Genetic Elements: Concepts and Applications CRC Press, Boca Raton, FL.

48. Park, S. M., Choi, E. S., Kim, M. J., Cha, B. J., Yang, M. S., and Kim, D. H. 2004. Characterization of HOG1 homologue, CpMK1, from Cryphonectria parasitica and evidence for hypovirus-mediated perturbation of its phosphorylation in response to hypertonic stress. Mol. Microbiol. 51:1267-1277.

49. Puhalla, J. E., and Anagnostakis, S. L. 1971. Genetic and nutritional requirements of Endothia parasitica. Phytopathology 61:169-173.

50. Ramamoorthy, V., Zhao, X. H., Snyder, A. K., Xu, J. R., and Shah, D. M. 2007. Two mitogen-activated protein kinase signalling cascades mediate basal resistance to antifungal plant defensins in Fusarium graminearum. Cell. Microbiol. 9:1491-1506.

51. Rigling, D., and Heininger, U., Hohl, H. R. 1989. Reduction of laccase activity in dsRNA-containing hypovirulent strains of Cryphonectria (Endothia) parasitica. Phytopathology 79:219-223.

52. Rostagno, L., Crivelli, G., and Turina, M. 2010. Study of mRNA expression by real time PCR of Cpkk1, Cpkk2 and Cpkk3, three MEKs of Cryphonectria parasitica, in virus-free and virus-infected isogenic isolates. J. Phytopathol. 158:409-416.

53. Rui, O., and Hahn, M. 2007. The Slt2-type MAP kinase Bmp3 of Botrytis cinerea is required for normal saprotrophic growth, conidiation, plant surface sensing and host tissue colonization. Mol. Plant Pathol. 8:173184.

54. Sambrook, J., Fritsch, E. F., and Maniatis, T. 1989. Molecular Cloning: A Laboratory Manual. Cold Spring Harbor Laboratory Press, Cold Spring Harbor, NY.

55. Schaeffer, H. J., and Weber, M. J. 1999. Mitogen-activated protein kinases: specific messages from ubiquitous messengers. Mol. Cell. Biol. 19:2435-2444

56. Segers, G. C., van Wezel, R., Zhang, X. M., Hong, Y. G., and Nuss, D. L. 2006. Hypovirus papain-like protease p29 suppresses RNA silencing in the natural fungal host and in a heterologous plant system. Eukaryot. Cell 5:896-904.

57. Segmuller, N., Ellendorf, U., Tudzynski, B., and Tudzynski, P. 2007. BcSAK1, a stress-activated mitogen-activated protein kinase, is involved in vegetative differentiation and pathogenicity in Botrytis cinerea. Eukaryot. Cell 6:211-221.

58. Takano, Y., Kikuchi, T., Kubo, Y., Hamer, J. E., Mise, K., and Furusawa, I. 2000. The Colletotrichum lagenarium MAP kinase gene CMK1 regulates diverse aspects of fungal pathogenesis. Mol. Plant-Microbe Interact. 13:374-383

59. Turina, M., Prodi, A., and Van Alfen, N. K. 2003. Role of the Mf1-1 pheromone precursor gene of the filamentous ascomycete Cryphonectria parasitica. Fungal Genet. Biol. 40:242-251.

60. Turina, M., and Rostagno, L. 2007. Virus-induced hypovirulence in Cryphonectria parasitica: still an unresolved conundrum. J. Plant Pathol. 89:165-178.

61. Turina, M., Zhang, L., and Alfen, N. K. 2006. Effect of Cryphonectria hypovirus 1 (CHV1) infection on Cpkk1, a mitogen-activated protein kinase kinase of the filamentous fungus Cryphonectria parasitica. Fungal Genet. Biol. 43:764-774. 
62. Wieser, J., Yu, J. H., and Adams, T. H. 1997. Dominant mutations affecting both sporulation and sterigmatocystin biosynthesis in Aspergillus nidulans. Curr. Genet. 32:218-224.

63. Xu, J. R. 2000. MAP kinases in fungal pathogens. Fungal Genet. Biol. 31:137-152.

64. Xu, J. R., and Hamer, J. E. 1996. MAP kinase and cAMP signaling regulate infection structure formation and pathogenic growth in the rice blast fungus Magnaporthe grisea. Genes Dev. 10:2696-2706.

65. Xu, J. R., Staiger, C. J., and Hamer, J. E. 1998. Inactivation of the mitogen-activated protein kinase Mps 1 from the rice blast fungus prevents penetration of host cells but allows activation of plant defense responses. Proc. Natl. Acad. Sci. USA 95:12713-12718.

66. Zhang, L., Baasiri, R. A., and Van Alfen, N. K. 1998. Viral repression of fungal pheromone precursor gene expression. Mol. Cell. Biol. 18:953-959.

67. Zhang, L., Churchill, A. C. L., Kazmierczak, P., Kim, D. H., and Van
Alfen, N. K. 1993. Hypovirulence-associated traits induced by a mycovirus of Cryphonectria parasitica are mimicked by targeted inactivation of a host gene. Mol. Cell. Biol. 13:7782-7792.

68. Zhang, L., Villalon, D., Sun, Y., Kazmierczak, P., and Van Alfen, N. K. 1994. Virus-associated down-regulation of the gene encoding cryparin, an abundant cell-surface protein from the chestnut blight fungus, Cryphonectria parasitica. Gene 139:59-64.

69. Zhao, X. H., Kim, Y., Park, G., and Xu, J. R. 2005. A mitogen-activated protein kinase cascade regulating infection-related morphogenesis in Magnaporthe grisea. Plant Cell 17:1317-1329.

70. Zhao, X. H., Mehrabi, R., and Xu, J. R. 2007. Mitogen-activated protein kinase pathways and fungal pathogenesis. Eukaryot. Cell 6:1701-1714.

71. Zheng, L., Campbell, M., Murphy, J., Lam, S., and Xu, J. R. 2000. The BMP1 gene is essential for pathogenicity in the gray mold fungus Botrytis cinerea. Mol. Plant-Microbe Interact. 13:724-732. 